\title{
Continuity equation and Gorlin formula compared with directly observed orifice area in native and prosthetic aortic valves
}

\author{
John B Chambers, David C Sprigings, Thomas Cochrane, John Allen, Richard Morris, \\ Martin M Black, Graham Jackson
}

\begin{abstract}
Orifice areas calculated by the continuity and Gorlin equations have been shown to correlate well in vivo. The continuity equation, however, gives underestimates compared with the Gorlin formula and it is not clear which is the more accurate. Both equations have therefore been tested against maximal orifice area measured by planimetry in eight prepared native aortic valves and four bioprostheses. A computer controlled, ventricular flow simulator (cycled at 70 beats/min) was used at five different stroke volumes that gave cardiac outputs of 2.8 to $7.01 / \mathrm{min}$. The mean difference between measured and estimated orifice area was zero for the continuity equation, but $-0.14 \mathrm{~cm}^{2}$ for the convential Gorlin formula. Thus the Gorlin formula tended to give overestimates compared with both measured area and area estimated by the continuity equation, probably because of the effect of pressure recovery. When predictive equations derived from these data were tested, residual standard deviations were around $0.3 \mathrm{~cm}^{2}$ at all stroke volumes for the continuity equation, around $0.2 \mathrm{~cm}^{2}$ for the invasive Gorlin formula, and between 0.2 and $0.4 \mathrm{~cm}^{2}$ for the modified Gorlin formula. These results suggest that estimates of orifice area in an individual valve as judged by any of the equations tested should be seen as a guide to rather than as a precise measure of actual orific area.
\end{abstract}

Pressure drop across an aortic valve depends on both transaortic flow and orifice area and is not on its own an adequate measure of stenosis. A better assessment of valve function can be obtained with flow-corrected estimated orifice area as found by, for example, the Gorlin formula. ${ }^{12}$ Recent work, however, has explored the application of the continuity equation, which is more suited to non-invasive studies. ${ }^{3-5}$ The continuity equation assumes that volume flow on either side of an obstruction is the same. A change in flow affects both sides equally so that the ratio of the two is independent of flow.
For the aortic valve, effective orifice area can be calculated as the product of subaortic to aortic flow velocity. ${ }^{6-8}$ Though good correlations have been shown between orifice area estimates by the continuity equation and the Gorlin formula, results from the continuity equation are usually lower. ${ }^{3} 10$ It is not known which equation is limited or whether both are.

We have therefore tested both the continuity equation and the Gorlin formula in native and bioprosthetic aortic valves mounted in a flow simulator, with directly observed orifice area as an independent standard.

\section{Methods}

VALVES

Eight native valves and four prostheses were tested. The latter comprised two unimplanted Mitroflow bovine pericardial prostheses (Mitral Medical, Canada), annulus diameters $23 \mathrm{~mm}$ and $25 \mathrm{~mm}$, and two explanted Carpentier-Edwards prostheses (American Edwards Laboratories, Baxter Healthcare, Santa Ana, CA, USA), diameter $23 \mathrm{~mm}$. One CarpentierEdwards prosthesis had been clinically normal (CE1) and the other was mildly stenotic and regurgitant (CE2). Two of the native valves were significantly stenotic, one bicuspid (explant 6), and the other tricuspid (explant 7). Two native valves were mildly stenotic (explants 3 and 8) and the other four were normal. The explanted native valves were excised attached to a cuff of aorta $3-5 \mathrm{~cm}$ long within six hours of death. All valves were stored at $4^{\circ} \mathrm{C}$ for one to eight weeks in a preservative solution containing fungicide and antibiotics. The explanted native valves were sewn on to a Teflon ring covered with brushed polyester and the aortic root was supported externally by aluminium stents fixed to each coronary sinus with epoxy resin (fig 1). After tests the valves were radiographed and the degree of calcification estimated semiquantitatively (table 1$).{ }^{11}$

\section{APPARATUS}

A positive displacement ventricular flow simulator controlled by computer was used. This was similar to the system described in detail elsewhere, ${ }^{12}$ but was modified by the

\author{
London SE1 9RT. \\ Accepted for publication \\ 4 June 1991 \\ Guy's Hospital, \\ R Morris \\ Correspondence to \\ Dr John B Chambers,
}


Figure 1 Preparation of an explanted aortic root and valve. The stenotic tricuspid native aortic valve (explant 7) is shown in profile $(A)$ and front view $(B)$. A mounting ring covered with teflon fabric has been sewn to the base of the aortic valve and three shaped aluminium stents fixed to the outside of the coronary sinuses with epoxy resins and a single stitch at the top of each stent.
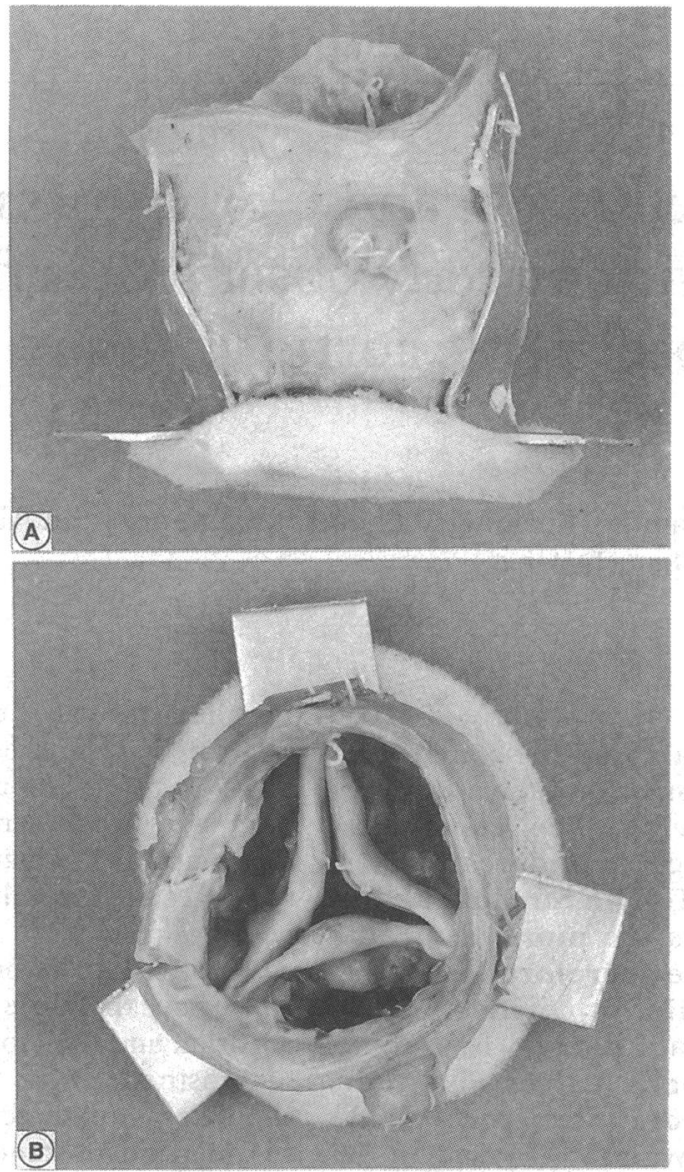

Table 1 Degree of calcification and subaortic area

\begin{tabular}{lll}
\hline & $\begin{array}{l}\text { Degree of } \\
\text { calcification }\end{array}$ & $\begin{array}{l}\text { Subaortic area } \\
\left(\mathrm{cm}^{2}\right)\end{array}$ \\
\hline Native valves explant: & & \\
1 & 0 & $3 \cdot 8$ \\
2 & 0 & $3 \cdot 5$ \\
3 & + & $4 \cdot 2$ \\
4 & 0 & $4 \cdot 5$ \\
5 & 0 & $2 \cdot 8$ \\
6 & ++++ & $3 \cdot 4$ \\
7 & +++ & $6 \cdot 2$ \\
8 & ++ & $4 \cdot 2$ \\
Prosthetic valves: & & \\
CE1 & 0 & $4 \cdot 5$ \\
CE2 & + & $4 \cdot 5$ \\
Mitroflow 23 mm & 0 & $4 \cdot 5$ \\
Mitroflow 25 mm & 0 & $4 \cdot 5$ \\
\hline
\end{tabular}

addition of an electromagnetic flowmeter placed $290 \mathrm{~mm}$ downstream from the sewing ring and by a removable aortic root (fig 2) which allowed easy insertion of the aortic valves. A copper tubular holder with an ultrasound pencil probe was inserted into a port in the end of the aortic section.

The system was filled with 121 of normal saline seeded with $5 \mathrm{ml}$ Sephadex. We used quasiphysiological drive waveform to give Doppler waveforms similar to those obtained in vivo (fig 3). A cycle rate of 70 beats $/ \mathrm{min}$ and stroke volumes of $40,55,70,85$, and $100 \mathrm{ml}$ were set with a constant systolic ejection time of $280 \mathrm{~ms}$ to give cardiac outputs of $2 \cdot 8-7 \cdot 0 \mathrm{l} / \mathrm{min}$ (mean transaortic flow $167-417 \mathrm{ml} / \mathrm{s}$ ). For the first four native valves only stroke volumes of
40,70 , and $100 \mathrm{ml}$ were used. The extra stroke volumes were included in subsequent tests to increase the number of data points. Transaortic flow was measured with an aortic electromagnetic flowmeter and pressure drop by strain gauge pressure transducers (Type 3EA Gaeltec, Dunvegan, Isle of Skye, UK) positioned $25 \mathrm{~mm}$ upstream and $100 \mathrm{~mm}$ downstream from the aortic prosthesis. Opening of the cusp $c$ was recorded by a video camera positioned perpendicularly to the plane of the valve. Strong foreground lighting maximised the contrast. Pressure drop, electromagnetic flowmeter measurements, continuous wave Doppler measurements, and video recordings of valve opening were made simultaneously before a second Doppler probe was inserted for separate recording of subvalvar velocity.

Doppler recordings were made with a Vingmed SD 50 Doppler system (Vingmed, Oslo, Norway). Aortic flow immediately distal to the valve orifice was recorded with continuous wave Doppler from an angled 1.9 MHz Pedof probe. This was held at an angle of about $20^{\circ}$ to the long axis of the aorta and then adjusted $ᄋ$ until the optimal signal was obtained (fig 2). An angle correction was not applied to the aortic velocity measurements. This introduced an underestimation in velocity of about $6 \%$ (cos $20^{\circ}$ ). Subaortic flow was recorded by a $5 \mathrm{MHz}$ in line probe. The tip of the probe was positioned in the centre of the artificial aortic section $3 \mathrm{~cm}$ downstream from the valve cusps in their closed position and protruded $2 \mathrm{~cm}$ beyond the end of the tubular holder (fig 2). We recorded subaortic flow by pulsed mode with the sample volume set at minimum length and placed within the ventricular chamber $1.0 \mathrm{~cm}$ from the mid-plane of the valve mounting ring.

\section{THEORETICAL ASSUMPTIONS}

If waveform configuration is assumed to be similar in the aorta and left ventricular outflow tract, the continuity equation based on the law of conservation of mass can be written:

$$
\left.A_{2}=A_{1} \times v_{1} / v_{2} \quad \text { (equation } 1\right)
$$

where $A_{1}$ is subaortic cross sectional area and $A_{2}$ maximal aortic orifice area in $\mathrm{cm}^{2}, \mathrm{v}_{1}$ is peak subaortic velocity, and $\mathrm{v}_{2}$ is peak aortic velocity in $\mathrm{m} / \mathrm{s}$.

The Gorlin formula for invasive use is ${ }^{12}$ :

$$
\mathrm{A}_{2}=\mathrm{Q} /\left(44.3 \times \mathrm{m} \Delta \mathrm{P}^{\frac{1}{2}}\right) \text { (equation 2) }
$$

where $Q$ is mean transaortic flow in $\mathrm{ml} / \mathrm{s}$ and $\mathrm{m} \Delta \mathbf{P}$ is the mean pressure drop in $\mathrm{mm} \mathrm{Hg}$. The correction constant, $44 \cdot 3$, may not be universally applicable so the formula was generalised to the expression:

$$
A_{2} \alpha Q / m \Delta P^{\frac{1}{2}}
$$

(equation 3)

In previous in vitro experiments with mitral bioprostheses, we showed an improvement in the correlation between measured and estimated orifice area when peak transvalvar velocity recorded by Doppler ultrasound was substituted for root mean pressure drop. ${ }^{12}$ 


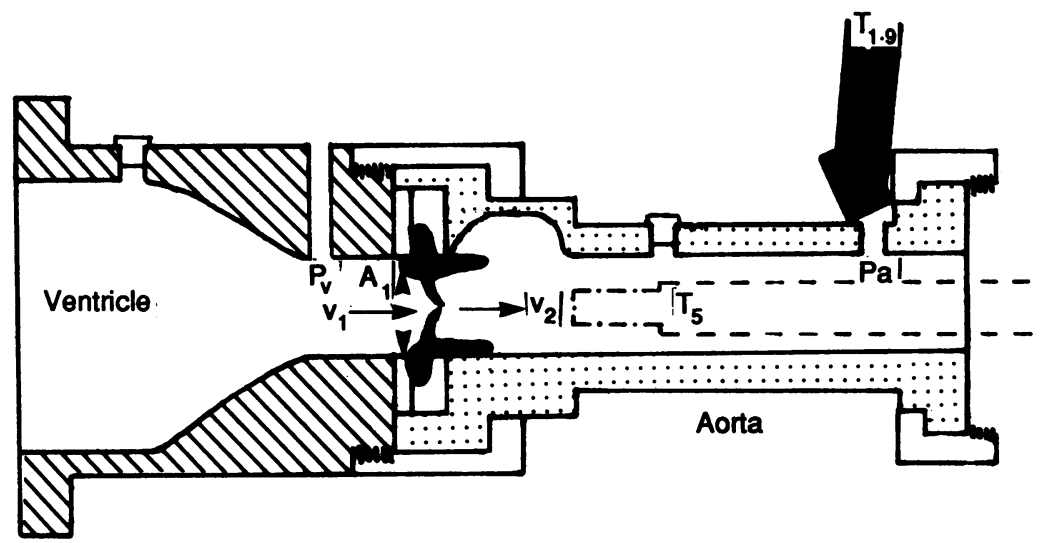

$10 \mathrm{~cm}$

Figure 2 Diagram of the ventricular outflow region and aortic root of the Sheffield flow simulator. From the continuity equation, estimated aortic valve orifice area $=A_{1} \times v_{1} / v_{2}$. $A_{1}$, subaortic cross sectional area $\left(\mathrm{cm}^{2}\right) ; P_{0}$ site of aortic pressure measurement; $P_{v}$, site of ventricular pressure measurement; $T_{1.9}$, Pedof $1.9 \mathrm{MHz}$ angled probe to record aortic flow $T_{5}, 5 \mathrm{MHz}$ pencil probe within a copper holder to record subaortic flow at the point of measurement of the subaortic area; $v_{1}$, subaortic velocity $(\mathrm{m} / \mathrm{s}) ; v_{2}$, aortic velocity $(\mathrm{m} / \mathrm{s})$.

Figure 3 Ultrasound recordings. Both recordings were made at stroke volume $70 \mathrm{ml}$, cycle rate 70 beats/min in the Carpentier-Edwards bioprosthesis (CE1). Figure $3 A$ shows subaortic velocity recorded with a $5 \mathrm{MHz}$ pencil probe in pulsed Doppler mode with the sample volume set at $1 \mathrm{~cm}$ below the cusps in their closed position. Figure $3 B$ shows aortic velocity recorded with a $1.9 \mathrm{MHz}$ Pedof probe. Peak velocity was taken as shown, from the best fit line through four complexes.
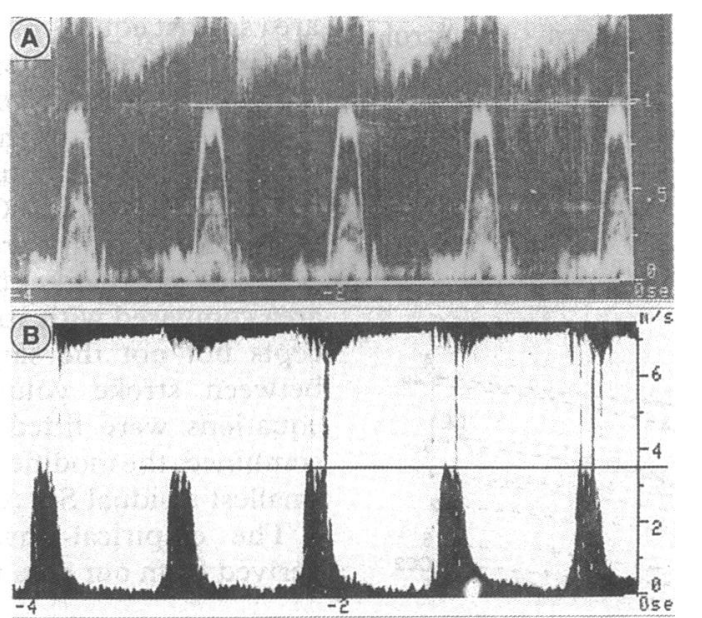

Therefore, in the present study, we also tested a similar modification:

\section{$\mathrm{A}_{2} \alpha \mathrm{Q} / \mathrm{Vmax} \quad$ (equation 4)}

where $\mathrm{V}$ max is peak transaortic velocity in $\mathrm{m} / \mathrm{s}$.

\section{DATA ANALYSIS AND STATISTICS}

The ultrasound signals were analysed manually and peak transaortic and subaortic velocities taken from the line of best fit through four cycles (fig 3). Transaortic flow was measured every five $m s$ by electromagnetic flowmeter and mean systolic flow was calculated. The video tape of cusp opening was monitored on an echocardiographic system (Hewlett Packard $77020 \mathrm{~A}$ ) and maximum orifice area was measured by planimetry using online analysis software (fig 4). The coefficients of variation for measurements of orifice area were calculated over 54 cycles at seven $(13 \%)$ of the data points. They ranged from 0.7 to $6.0 \%$ with a median of $1 \cdot 0 \%$. Orifice measurements were corrected for magnification by a factor calculated from the known area of the valve mounting rings.

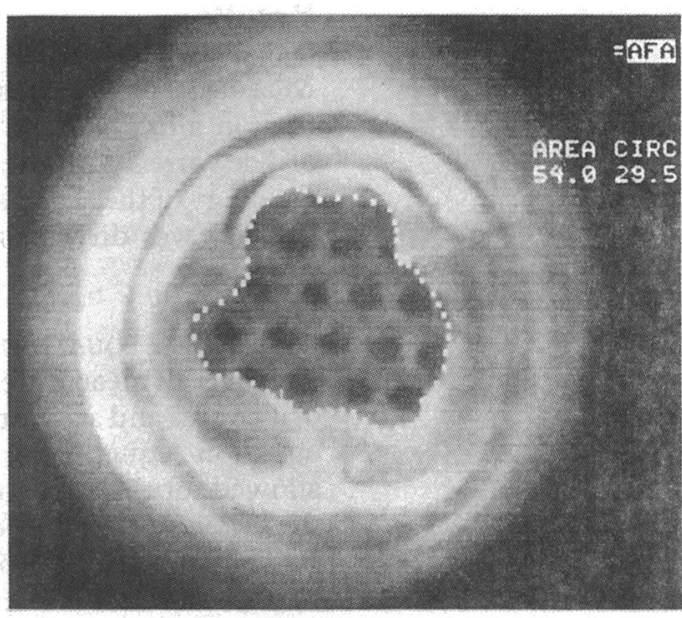

Figure 4 Maximal orifice in a Carpentier-Edwards aortic prosthesis. The frame was recorded at stroke volume $70 \mathrm{ml}$, cycle rate 70 beats/min in the valve CE1. The white dots are points used to measure directly observed orifice area from a digitised video image by means of the online software of an ultrasound system (Hewlett-Packard 77020A).

In some valves the sewing fabric enroached into the left ventricular outflow tract. Subaortic cross sectional area was, therefore, calculated by planimetry of video recordings of the inflow aspect of the mounted valves. To check the reliability of fluid velocity measurements recorded by Doppler ultrasound, they were compared with the peak pressure drop by means of the simplified Bernoulli relation assuming negligible subaortic velocity ${ }^{13}$ (peak pressure drop $(\mathrm{mm} \mathrm{Hg}) \alpha \mathrm{Vmax}^{2}$ where Vmax is peak transaortic velocity in $\mathrm{m} / \mathrm{s}$. The correlation between pressure drop and the square of peak velocity was good $\left(r=0.96, S D_{\text {res }} 63\right.$; $\mathrm{y}=4 \cdot 7+3 \cdot 1 \mathrm{x})$ (fig 5).

Agreement between measured and calculated orifice areas was expressed by calculating the mean and $95 \%$ confidence intervals ( $95 \%$ CIs) for the differences between paired values. Because 12 different valves were tested at five different stroke volumes, analysis of variance for repeated measurements was performed with valve and stroke volume as factors. Prediction equations and residual standard deviations (SDs) were calculated for each stroke volume.

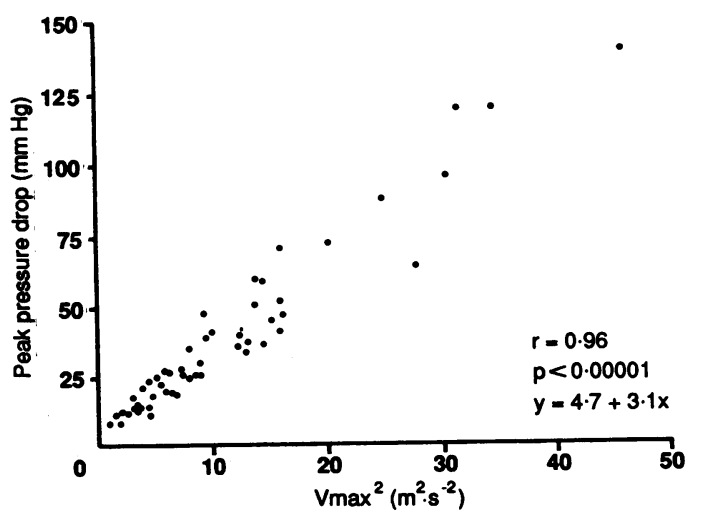

Figure 5 Plot of peak pressure drop against the square of peak transaortic velocity. 


\section{Results}

CUSP BEHAVIOUR

Measured orifice area was directly related to flow in all valves (fig 6) and the shape of the orifice varied with the type of prosthesis or the aetiology of the aortic stenosis (fig 7). Subaortic velocity was directly related to stroke volume (fig 8).

\section{CONTINUITY EQUATION}

The overall mean difference between measured orifice area and area estimated by the continuity equation (equation 1) was $0.00 \mathrm{~cm}^{2}$. After we allowed for the effect of the 12 different valves, the difference was dependent on stroke volume $\left(F_{4,36}=8.49, p<0.005\right)$. Mean difference at stroke volumes of $40,55,70,85$, and $100 \mathrm{ml}$ were $-0 \cdot 13,-0 \cdot 10,0 \cdot 05,-0 \cdot 01$, and $0 \cdot 16 \mathrm{~cm}^{2}$ respectively. Thus the continuity equation tended to give underestimates at higher and overestimates at lower stroke volumes.

\section{GORLIN FORMULA}

The overall mean difference between measured orifice area and area estimated with the conventional Gorlin formula (equation 2) was $-0.14 \mathrm{~cm}^{2}$. Mean differences at stroke

Figure 6 Plot of maximal orifice area against flow. Data points from all eight native and all four bioprosthetic aortic valves are included.

Figure 7 Maximal orifice areas. These were recorded in three native explants (one normal (explant 5), one mildly calcified (explant 3) and one heavily calcified (explant 7), a Carpentier-Edwards bioprosthesis (CE1), and a Mitroflow bovine pericardial prosthesis (MF 25)). Orifice areas are shown at no flow then at stroke volumes of 40 , 70 , and $100 \mathrm{ml}$ with a cycle rate of 70 beats/min.

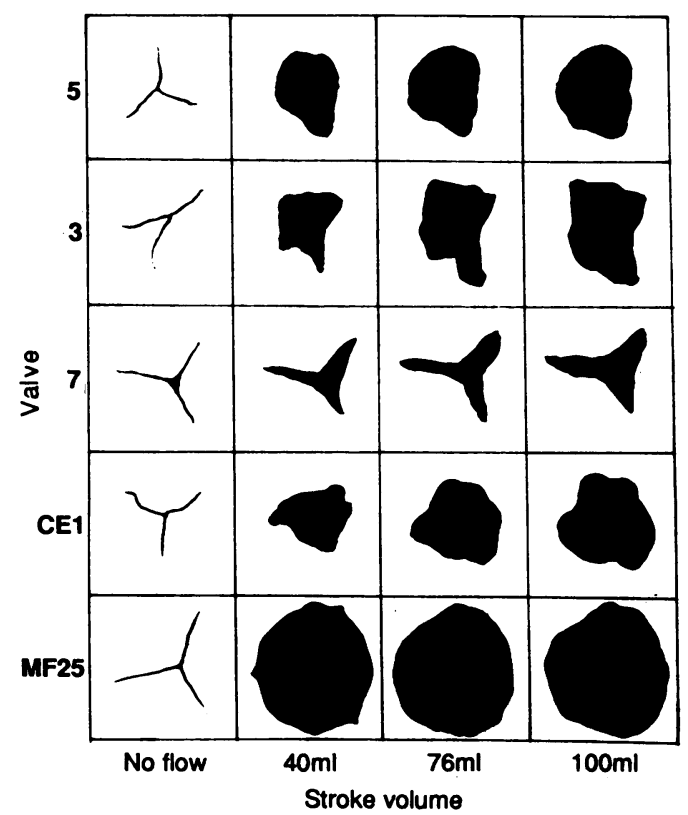

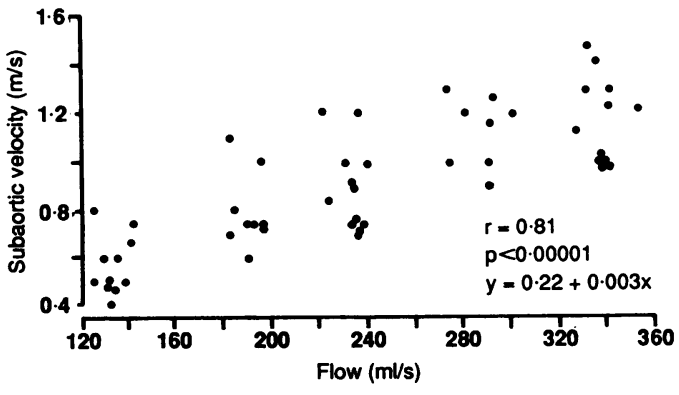

Figure 8 Plot of peak subaortic velocity against mean systolic flow.

volumes of $40,55,70,85$, and $100 \mathrm{ml}$ were 0.04 , $-0 \cdot 15,-0.09,-0.18$, and $-0.33 \mathrm{~cm}^{2}$. Thus the Gorlin formula tended to overestimate measured orifice area especially at higher stroke volumes.

\section{EMPIRICAL PREDICTION OF MEASURED ORIFICE} AREA

Figures 9 and 10 show plots of measured orifice area against equations 1,3 , and 4 . Table 2 gives the prediction equations calculated from these data for each stroke volume. Residual SD was about $0.3 \mathrm{~cm}^{2}$ for the continuity equation, about $0.2 \mathrm{~cm}^{2}$ for the invasive Gorlin formula, and between 0.2 and $0.4 \mathrm{~cm}^{2}$ for the modified Gorlin formula. Figure 11 shows the differences between measured and calculated orifice area compared with stroke volume. The intercepts but not the slopes varied significantly between stroke volumes. When prediction equations were fitted for all stroke volumes combined, the modified Gorlin formula had the smallest residual SD (equation 4).

The empirical invasively based formula derived from our data was:

$$
A_{2}=Q /\left(52.6 \times m \Delta P^{\frac{1}{2}}\right)(\text { equation } 5)
$$

The use of the convential constant, $44 \cdot 3$, would therefore have led to overestimation of orifice area by a factor of 1.18 in all valves considered together. The factor varied between 0.85 and 1.32 when calculated for each valve individually.

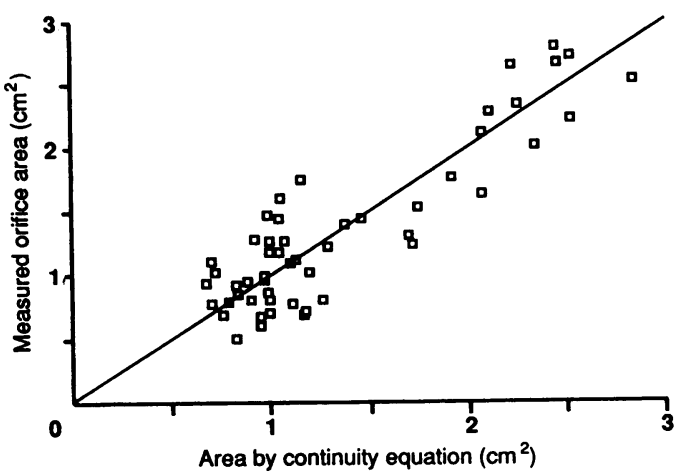

Figure 9 Continuity equation: measured orifice area compared with area estimated by the continuity equation. The line of identity is shown. 
Figure 10 The Gorlin relation. (A) The invasively derived relation (equation 3). (B) The Gorlin relation modified for use with ultrasound (equation 4).
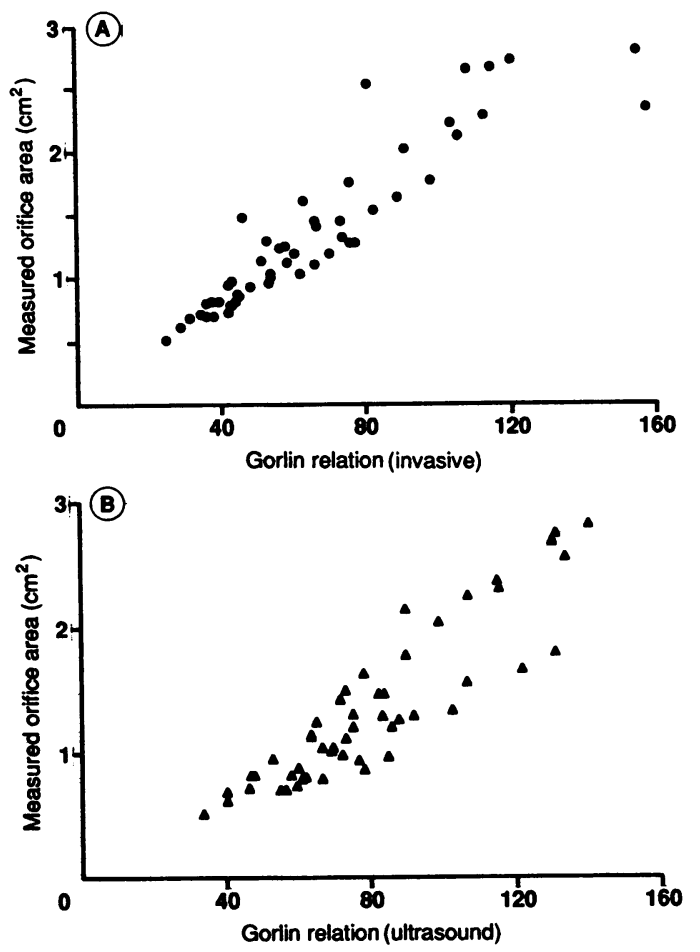

Table 2 Comparison of regression lines fitted to predict measured orifice area at different stroke volumes using three equations (residual $S D$ )

\begin{tabular}{|c|c|c|c|c|}
\hline \multicolumn{5}{|c|}{ Stroke volumes ( $\mathrm{ml}$ ) } \\
\hline $\begin{array}{l}40 \\
(n=12)\end{array}$ & $\begin{array}{l}55 \\
(n=8)\end{array}$ & $\begin{array}{l}70 \\
(n=12)\end{array}$ & $\begin{array}{l}85 \\
(n=8)\end{array}$ & $\begin{array}{l}100 \\
(n=12)\end{array}$ \\
\hline \multicolumn{5}{|c|}{ Continuity equation (equation1) } \\
\hline $\begin{array}{c}0.1+0.78 x \\
(0.29)\end{array}$ & $\begin{array}{c}-0.4+1.2 x \\
(0.29)\end{array}$ & $\begin{array}{c}0.2+0.86 x \\
(0.29)\end{array}$ & $\begin{array}{c}-0.06+1.03 x \\
(0.25)\end{array}$ & $\begin{array}{c}0.23+0.95 x \\
(0.27)\end{array}$ \\
\hline \multicolumn{5}{|c|}{ Invasive Gorlin generalisation (equation 3) } \\
\hline $\begin{array}{c}-0.3+0.03 x \\
(0.25)\end{array}$ & $\begin{array}{c}-0.2+0.02 x \\
(0.21)\end{array}$ & $\begin{array}{c}-0.1+0.02 x \\
(0.18)\end{array}$ & $\begin{array}{c}-0.02+0.02 x \\
(0.15)\end{array}$ & $\begin{array}{l}0.3+0.02 x \\
(0.19)\end{array}$ \\
\hline \multicolumn{5}{|c|}{ Modified Gorlin generalisation (equation 4) } \\
\hline $\begin{array}{c}-0.4+0.02 x \\
(0.20)\end{array}$ & $\begin{array}{c}-0.5+0.02 x \\
(0.36)\end{array}$ & $\begin{array}{c}-0.4+0.02 x \\
(0.28)\end{array}$ & $\begin{array}{c}-0.3+0.02 x \\
(0.33)\end{array}$ & $\begin{array}{c}-0.2+0.02 x \\
(0.30)\end{array}$ \\
\hline
\end{tabular}

\begin{abstract}
Discussion
Several studies have compared estimates of orifice area by the Gorlin and continuity equations in the clinical situation. These have shown good correlations in routine studies ${ }^{347}$ or before and after balloon dilatation, ${ }^{9}$ but the continuity equation has tended to give an underestimate compared with the Gorlin equation. In the present study, the conventional Gorlin formula (equation 2) overestimated orifice area, when compared with measured area, whereas the continuity equation gave a mean difference of zero. Thus in previously published studies it is likely that overestimates were given by the Gorlin formula rather than underestimates by the continuity equation.
\end{abstract}

SOURCES OF ERROR IN THE GORLIN FORMULA The most important cause for systematic overestimation of orifice area by the Gorlin formula is likely to have been neglect of pressure recovery. Because fluid loses momentum beyond an orifice, kinetic energy is converted to
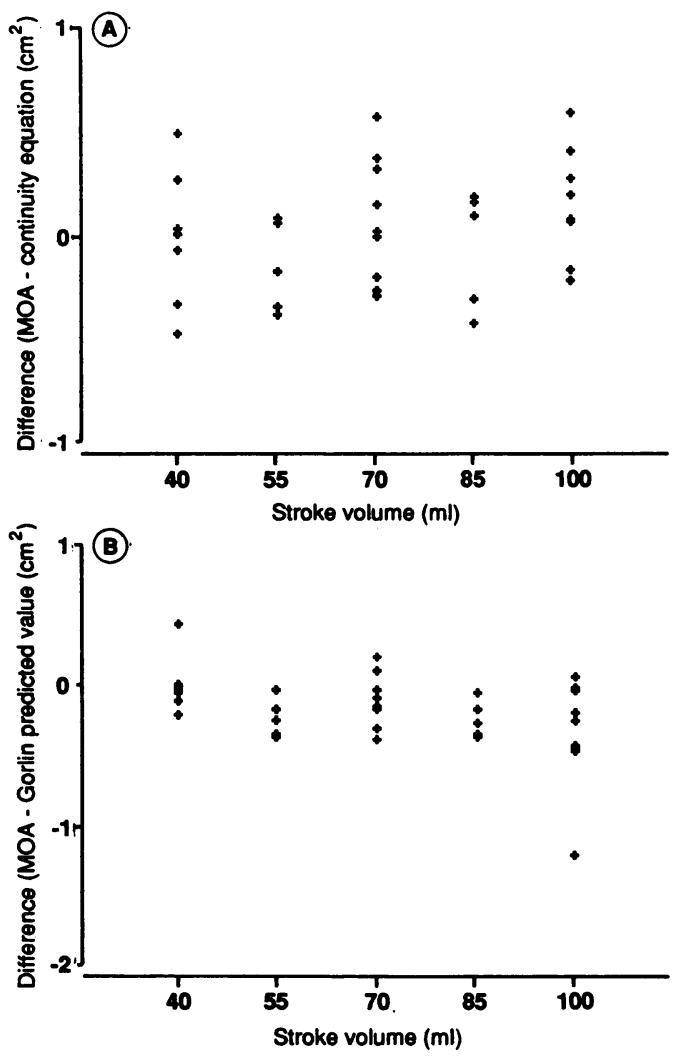

Figure 11 Differences between measured (MOA) and estimated orifice area. Values are grouped by stroke volume for the contuinity equation $(A)$ and invasive Gorlin formula (fig 11B).

pressure energy. Static pressure increases and ultimately approaches its prestenotic value, although complete recovery is limited as a result of changes in chamber geometry and because some energy is lost through turbulence. ${ }^{14}$ In our system, the pressure transducer was located $100 \mathrm{~mm}$ downstream from the annulus of the valves at a point where pressure recovery would have been complete. The situation in clinical practice is similar because a fluid filled catheter must be positioned beyond the point where "whip" artefact makes pressure recordings unreliable. Underestimation of the transaortic pressure drop is accentuated when femoral artery pressure rather than aortic pressure is measured. ${ }^{10}$ Other possible sources of error are the difference in density between blood and physiological saline (although by a factor of only 1.05 ), the use of root mean pressure drop instead of the mean of root pressure drop, and changes in the correction constant at extremes of flow. ${ }^{14} 15$

Our results differ from those of Segal et al who showed that the Gorlin formula tended to underestimate compared with the continuity equation. ${ }^{15}$ In that study the pressure transducer was placed close to the orifice so that pressure recovery would have been small. Underestimation could have been caused mainly by a fall in discharge coefficient (this implies an increase in pressure drop as a result of viscous friction) at Reynold's numbers below a critical value. This value was shown to be directly related to orifice area and in that 
experiment areas up to $4.5 \mathrm{~cm}^{2}$ were used; these were larger than in the present study.

The average overestimation of orifice area calculated from our regression equation was 1 2. Correction factors calculated for individual valves, however, ranged from 0.9 to $1 \cdot 3$. Hence variability in estimated orifice area was increased by the use of an average value. Other workers have also shown that discharge coefficients vary between valves and depend on the geometry and area of the orifice..$^{16}$ The same problem would affect the accuracy of the Gorlin formula in the clinical situation.

SOURCES OF ERROR IN THE CONTINUITY EQUATION The continuity equation is not limited by the effect of pressure recovery because velocity can be measured in line with flow, and peak instantaneous velocity can be assumed to have been recorded at the point of maximum pressure drop. Thus in the present study the mean difference between estimated and measured orifice area was zero.

Residual SDs were around $0.3 \mathrm{~cm}^{2}$, which means that orifice area may be predicted to within $0.6 \mathrm{~cm}^{2}$ for $95 \%$ of individual readings. The equation tended to underestimate at high and overestimate at low stroke volumes. These discrepancies are difficult to explain. The cause of overestimation may have been erroneously low peak transvalvar velocity measurements, although the fact that the relation between peak pressure drop and peak instantaneous velocity did not vary significantly makes this unlikely. Underestimation could theoretically be caused by erroneously low subaortic velocities although these seemed to change consistently with flow in each prosthesis (fig 8). Possibly changes in stroke volume caused differences in convective flow acceleration in the subaortic region, ${ }^{17}$ while the position of the pulsed wave sample volume remained fixed.

\section{VALIDITY OF MEASURED ORIFICE AREA}

The validity of directly observed orifice area as a reference standard depends on three factors: the accuracy of its calculation, whether maximal area is more appropriate than mean area, and on the relation between hydrodynamic and anatomical orifice area.

There may have been small errors in measurement where the edges of the orifice were irregular. This, however, was only a potential problem in three valves (explants 6 and 8 and CE 2). The image used for planimetry, furthermore, was magnified so that any errors were reduced by a factor of about 40 ; this made them insignificant.

Effective area calculated by the Gorlin formula uses the square root of mean pressure drop. This is unlikely to have caused major inconsistencies because normal native aortic valves open and close quickly, within approximately $30 \mathrm{~ms}$, and therefore remain at maximum area through most of systole. ${ }^{16}$ Also, the use of peak transaortic velocity, which occurs at the same time as maximum orifice area, in the modified Gorlin formula did not improve the correlation with actual orifice area.
Anatomical orifice area measured by planimetry may differ from effective hydrodynamic orifice area in some circumstances. In stenotic valves flow lines continue to converge beyond the orifice as far as the vena contracta. At this point the pressure drop will be greater than at the orifice and the hydrodynamic orifice area will be correspondingly smaller than the measured orifice area. Normally functioning bioprostheses behave as nozzles. They do not develop a vena contracta but have mechanical energy losses that depend on the shape of the nozzle. These increase the transvalvar pressure drop so that, again, effective orifice area is smaller than orifice area measured by planimetry. ${ }^{18}$ Thus, in general, effective orifice area is expected to be slightly smaller than measured orifice area although the Gorlin formula contains constants intended to correct for this difference.

Measured orifice area as used in this study is not a perfect reference standard. The errors in its measurement are, however, small and although differences in valve shape and behaviour may have contributed to inconsistencies between anatomical and hydrodynamic orifice area, this effect is not expected to have been large.

\section{LIMITATIONS}

In the Sheffield flow simulator, the volume flow rate is constrained but the pressure that can be developed within the ventricle is not limited. The left ventricular outflow tract and aortic root have a shape similar to that of the real heart, but are rigid. Thus although physiological waveforms, peripheral compliance, and peripheral resistance are modelled to first order, the simulator is not a perfect representation of the real heart. The native valves were mounted in a rigid annulus by means of a sewing ring and aluminium stents and their behaviour may have differed in detail from native valves in vivo.

The presence of the ultrasound probe holder should not have introduced errors as it was used solely for recording subaortic velocity. Although its presence may have caused flow acceleration, this would have begun about $6 \mathrm{~cm}$ downstream from the point of velocity measurement. Orifice area and peak aortic velocity measurements were made with the holder removed. The angle subtended between the probe and the axis of the aorta would have caused an underestimation of flow velocity and therefore an overestimation of orifice area of about $6 \%$.

Despite the artificial nature of the model, the wide tolerance limits for paired values in this study almost certainly reflect clinical reality. Thus in the study of Oh et al, $27 \%$ of patients had discrepancies between the continuity equation and Gorlin formula in the diagnosis of aortic valves with effective areas of less than $0.75 \mathrm{~cm}^{2}{ }^{7}$ Standard errors of the estimate for the comparison between the Gorlin formula and continuity equation in published studies range from $0 \cdot 16$ to $0 \cdot 40 .^{36-9}$ In the present study standard errors were around 0.01 for comparisons between estimated and measured orifice area. 


\section{CLINICAL RELEVANCE}

An orifice area estimate has relatively wide CIs so that it should not be used alone in making clinical decisions. Thus Kennedy et al studied patients with aortic stenosis, which was defined as moderate solely on the basis of an orifice area estimate of between 0.7 and $1.2 \mathrm{~cm}^{2}$ from the Gorlin formula. ${ }^{19}$ The fact that $82 \%$ had symptoms and the four year prognosis was poor suggests that the degree of stenosis may have been underestimated. A balanced judgement about the degree of disease has to be made based on numerous criteria including the clinical assessment, the state of the left ventricle, and the transvalvar velocity as well as the estimated orifice area.

\section{CONCLUSION}

In this study, the empirically derived Gorlin constant was higher than the conventional term probably because of the effect of pressure recovery. The regression line of the continuity equation for measured orifice area against estimated orifice area was close to the line of identity. When compared in a population of valves, therefore, the conventional Gorlin formula is expected to overestimate and the continuity equation to be similar to measured orifice area. The $95 \%$ CIs of either the empirically derived Gorlin formula or the continuity equation were wide. This suggests that both formulas should be regarded as providing a semiquantitative guide rather than a precise measure of orifice area.

JBC was supported by a grant from the Peel Medical Trust. We thank the workshop of the Department of Medical Physics and Clinical Engineering at the Hallamshire Hospital for modifying the pulse-duplicator system and Mitral Medical for donating the unimplanted prostheses.

1 Gorlin R, Gorlin SG. Hydraulic formula for calculation of the area of the stenotic mitral valve, other cardiac valves, and central circulatory shunts. Am Heart J 1951; 41:1-29.

2 Cohen MV, Gorlin R. Modified orifice equation for the calculation of mitral valve area. Am Heart $J$ 1972;84: 839-40.
3 Zoghbi WA, Farmer KL, Soto JG, Nelson JG, Quinones MA. Accurate noninvasive quantification of stenotic aortic valve area by Doppler echocardiography. Circulation 1986;73:452-9.

4 Teirstein P, Yeager M, Yock P, Popp RL. Doppler echocardiographic measurement of aortic valve area in aortic stenosis: a noninvasive application of the Gorlin formula. J Am Coll Cardiol 1986;8:1059-65.

5 Richards KL, Cannon SR, Miller JF, Crawford MH. Calculation of aortic valve area by Doppler echocardioCalculation of aortic valve area by Doppler echocardio-
graphy: a direct application of the continuity equation. Graphy: a direct application

6 Skjaerpe T, Hegrenaes L, Hatle L. Non-invasive estimation kjaerpe $T$, Hegrenaes $L$, Hatle L. Non-invasive estimation
of valve area in patients with aortic stenosis by Doppler ultrasound and two dimensional echocardiography. Circulation 1985;72:810-8.

7 Oh JK, Taliercio CP, Holmes DR, Reeder GS, Bailey KR, Seward JB, et al. Prediction of the severity of aortic stenosis by Doppler aortic valve area determination: prospective Doppler-catheterization correlation in 100 patients. J Am Coll Cardiol 1988;11:1227-34.

8 Otto CM, Pearlman AS, Comess KA, Reamer RP, Janko CL, Huntsman LL. Determination of the stenotic aortic valve area in adults using Doppler echocardiography. J Am Coll Cardiol 1986;7:509-17.

9 Come PC, Riley MF, McKay RG, Safian R. Echocardiographic assessment of aortic valve area in elderly patients with aortic stenosis and of changes in valve area after percutaneous balloon valvuloplasty. J Am Coll Cardiol percutaneous ball

10 Goli VD, Teague SM, Prasad R, Harvey J, Voyles WF, Olson EG, et al. Noninvasive evaluation of aortic stenosis Olson EG, et al. Noninvasive evaluation of aortic stenosis severity utilizing Doppler ultrasound and electr
impedance. $J$ Am Coll Cardiol 1988;11:66-71.

11 Schoen FJ, Kujovich JL, Webb CL, Levi RJ. Chemically determined mineral content of explanted porcine valve bioprostheses: correlation with radiographic assessment of calcification and clinical data. Circulation 1987;76: 1061-6.

12 Chambers JB, Cochrane T, Black MM, Jackson G. The Gorlin formula validated against directly observed orifice area in porcine mitral bioprostheses. $\mathrm{J} \mathrm{Am} \mathrm{Coll} \mathrm{Cardiol}$ 1989;13:348-53.

13 Stamm RB, Martin PR. Quantitification of pressure gradients across stenotic valves by Doppler ultrasound. $J$ Am Coll Cardiol 1983;2:707-18.

14 Tindale WB, Trowbridge EA. Modification of the Gorlin equation for use with heart valve substitutes. Cardiovasc Res 1986;20:458-65.

15 Segal J, Lerner DJ, Miller DC, Mitchell RS, Alderman EA. Popp RL. When should Doppler-determined valve area be better than the Gorlin formula?: variation in hydraulic constants in low flow states. J Am Coll Cardiol 1987; 9:1294-305.

16 Thubrikar M, Bosher LP, Nolan SP. The mechanism of opening of the aortic valve. $J$ Thorac Cardiovasc Surg opening of the

17 Pasipoularides A, Murgo JP, Bird JJ, Craig WE. Fluid dynamics of aortic stenosis: mechanisms for the presence
of subvalvular pressure gradients. Am J Physiol 1984; 246:H542-50.

18 Clark C. The fluid mechanics of aortic stenosis: I Theory and steady flow experiments. II Unsteady flow experiments. $J$ Biomech 1976;9:521-8, 567-73.

19 Kennedy KD, Nishimura RA, Holmes DR, Bailey KR. Natural history of moderate aortic stenosis. J Am Coll Cardiol 1991;17:313-9. 